\title{
Lymph node ratio, but not the total number of examined lymph nodes or lymph node metastasis, is a predictor of overall survival for pancreatic neuroendocrine neoplasms after surgical resection
}

\author{
Peng Liu ${ }^{1, *}$, Xianbin Zhang ${ }^{1,2,}{ }^{*}$, Yuru Shang ${ }^{1}$, Lili Lu ${ }^{3}$, Fei Cao ${ }^{1}$, Min Sun ${ }^{4}$, Zhaohui \\ Tang ${ }^{5}$, Brigitte Vollmar ${ }^{2}$ and Peng Gong ${ }^{1,6}$ \\ ${ }^{1}$ Department of Hepatobiliary Surgery, The First Affiliated Hospital of Dalian Medical University, Dalian, 116011, China \\ ${ }^{2}$ Institute of Experimental Surgery, University of Rostock, Schillingallee 69a, Rostock, 18059, Germany \\ ${ }^{3}$ Department of Epidemiology, Dalian Medical University, Dalian, 116044, China \\ ${ }^{4}$ Department of Oncology, Zhongnan Hospital of Wuhan University, Hubei Key Laboratory of Tumor Biological Behaviors and \\ Hubei Cancer Clinical Study Center, Wuhan, 430071, China \\ ${ }^{5}$ Department of General Surgery, Xinhua Hospital Shanghai Jiaotong University, Shanghai, 200092, China \\ ${ }^{6}$ Dalian Key Laboratory of Hepatobiliary Pancreatic Diseases Prevention and Treatment and Liaoning Key Laboratory of \\ Molecular Targeted Drugs in Hepatobiliary and Pancreatic Cancer, Dalian, 116011, China \\ *These authors contributed equally to this work \\ Correspondence to: Xianbin Zhang, email: zhangxianbin@hotmail.com \\ Peng Gong, email: gongpengdalian@163.com
}

Keywords: pancreatic neuroendocrine neoplasms, lymph node ratio, examined lymph nodes, lymph node metastasis, overall survival

Received: January 18, 2017

Accepted: June 28, 2017

Published: July 12, 2017

Copyright: Liu et al. This is an open-access article distributed under the terms of the Creative Commons Attribution License 3.0 (CC BY 3.0 ), which permits unrestricted use, distribution, and reproduction in any medium, provided the original author and source are credited.

\section{ABSTRACT}

Aim: To evaluate the prognostic significance of lymph node metastasis, extent of examined lymph nodes (ELNs) and lymph node ratio (LNR) for resected pancreatic neuroendocrine neoplasms (pNENs).

Materials and Methods: Surgically resected pNENs were assimilated from the Surveillance, Epidemiology, and End Results database. Kaplan-Meier and Cox proportional hazard models were used to examine the prognostic effect of clinicopathological characteristics on overall survival; Harrell's concordance index was performed to assess the prognostic accuracy of all independent prognostic factors; and the Spearman's rank correlation was used to assess the correlation between LNR and other clinicopathological characteristics.

Results: Totally, 1,273 pathologically confirmed pNENs were included in our study. The extent of ELNs failed to show any survival benefit in entire cohort (ELNs $\leq$ 12 vs. ELNs $>12, P=0.072$ ) or pNENs without lymph node metastasis (ELNs $\leq 28$ vs. ELNs $>28, P=0.108$ ). Lymph node metastasis and LNR $>0.40$ were significantly (both $P<0.001$ ) adverse prognostic factors of overall survival. However, only LNR $>0.40$ was the independent predictor of survival after adjusted for other clinicopathological characteristics. Besides LNR, the age, gender, primary tumor site, grade and stage also were the independent predictors of overall survival; and this survival model had an acceptable predictive power (Harrell's concordance index, $\mathbf{0 . 7 3 1}$ ).

Conclusions: The current study suggested that the LNR, not the total number of ELNs and the lymph node metastasis, is an independent prognostic indicator of overall survival for pNENs after surgical resection. 


\section{INTRODUCTION}

Pancreatic neuroendocrine neoplasms (pNENs), also known as pancreatic endocrine tumors, islet cell neoplasms or islet cell carcinomas, are rare tumors with an annual incidence of $0.19 / 100,000-0.32 / 100,000$ [1-3]. However, compared to 1973 , the incidence of NENs in 2004 has increased 382\% in United States [3]. Although pNENs are associated with relatively indolent physiological behavior, most patients eventually succumb to mortality due to the disease $[4,5]$.

Lymph node metastasis is commonly used as a critical prognostic factor for predicting survival and disease progression of pancreatic ductal adenocarcinomas (PDAC) and pNENs [6-9]. However, some studies showed that lymph node metastasis was not an independent prognostic factor of PDAC and pNENs $[10,11]$. The accuracy of staging lymph node was directly proportional to the number of examined lymph nodes (ELNs), and many studies suggested that the extent of ELNs was significantly associated with survival of PDAC, especially in patients without lymph node metastasis [12-14]. Moreover, lymph node ratio (LNR), the number of metastatic lymph nodes divided by the total number of ELNs, was increasingly recognized as a more powerful prognostic factor than lymph node metastasis in PDAC $[10,11,15]$, intraductal papillary mucinous [16], and ampullary carcinoma [17, 18].

However, the benefit of ELNs in pNENs is still unclear; and the role of LNR in predicting survival is contradictory. Boninsegna et al. [19] and Ricci et al. [20] proposed that LNR $>0.20$ and LNR $>0.07$, respectively, was the robust predictor of recurrence of pNENs. On the other hand, Murakami et al. [8] found that LNR $>0.20$ did not correlate with poor overall survival (OS). These contradictory results might be attributed to the relative rarity of the samples and the cut-off values of LNR in these studies, which limited the identification of LNR in survival.

The Surveillance, Epidemiology, and End Results (SEER) database is an authoritative source of information with high-quality cancer registries, established in 1973, encompassing approximately $28 \%$ of the USA population. All the malignant cases were followed-up annually to determine the vital status. The large population and completed follow-up of SEER program can be safely speculated to represent the total USA population.

The aim of the present study was to use a large population to evaluate the predictive role of ELNs, lymph node metastasis, and LNR in OS of pNENs after surgical resection. Furthermore, we attempted to establish the correlation between LNR and clinicopathological characteristics (tumor size, grade, and stage).

\section{RESULTS}

\section{Patients' characteristics}

A total of 1,273 pathologically confirmed pNENs comprising of 680 males and 593 females, were included in our study (Figure 1). The median age and interquartile range (IQR) at diagnosis were 58 years (49 years-67 years). Approximately, $80 \%$ patients were ethnically Caucasians. The degree of tumor localized at the head was similar to that of the tail $(32.8 \%$ and $36.8 \%$ of all patients, respectively, head-to-tail ratio, 0.89:1). Approximately, $60.0 \%$ of patients underwent partial pancreatectomy. The tumor size in $73.0 \%$ patients was larger than $2.0 \mathrm{~cm}$. The median of ELNs was 10 (IQR, 5-16), and 42.0\% patients with lymph node metastasis. The median of LNR was 0 (IQR, 0-0.2); 61.6\% patients exhibited SEER grade I. The proportion of AJCC TNM stage I and stage II were $38.7 \%$ and $40.3 \%$, respectively (Table 1 ).

\section{The lymph node metastasis and overall survival}

As we assumed, the OS of the patients with lymph node metastasis ( 82.965 months \pm 2.504 months) was significantly $(P<0.001)$ shorter than that of patients without metastasis (97.615 months \pm 2.086 months) (Figure 2A). The univariate analysis showed the lymph node metastasis significantly $(P<0.001)$ increased the risk of death (HR 1.914, 95\% CI: 1.467-2.497). However, the multivariate analysis failed to display that the lymph node metastasis was associated with OS (Table 2).

\section{The extent of examined lymph nodes and overall survival}

The most appropriate cut-off value of ELNs for entire cohort and the patients without lymph node metastasis were 12 and 28, respectively. Surprisingly, we found that the extent of ELNs was not a significantly beneficial survival factor in either entire cohort (ELNs $\leq 12$ vs. ELNs $>12,92.363$ months \pm 1.978 months vs. 85.285 months \pm 2.582 months, $P=0.072$ ) (Figure 2B) or in patients without lymph node metastasis (ELNs $\leq 28$ vs. ELNs $>28,98.231$ months \pm 2.106 months vs. 72.246 months \pm 9.734 months, $P=0.108$ ) (Figure 2C).

\section{The lymph node ratio and overall survival}

The most appropriate cut-off value of LNR was 0.40 in our study; and we found that compared to the OS of patients with $\mathrm{LNR}=0$ (97.615 months \pm 2.086 months $)$ and $0<\mathrm{LNR} \leq 0.40$ (86.468 months \pm 3.006 months), LNR $>0.40$ exhibited significantly $(P<0.001 ; P=0.025$; respectively) shorter OS (75.473 months \pm 4.287 months) (Figure 3A). The multivariate analysis showed that LNR $>0.40$ was an independent prognostic factor $(\mathrm{HR}=1.650$, $95 \%$ CI: $1.117-2.438, P=0.012$ ) (Table 2).

We also evaluated the predictive role of LNR $>0.2$ and LNR $>0.07$ reported by Boninsegna et al. [19] and Ricci et al. [20], respectively. We found that compared to the OS of patients with $\mathrm{LNR}=0$ (97.615 months \pm 2.086 months), patients with LNR $>0.2$ and LNR $>0.07$ 


\begin{tabular}{|c|c|c|}
\hline \multirow[b]{2}{*}{ Characteristic } & \multicolumn{2}{|c|}{ Patients $(N=1273)$} \\
\hline & No. & $\%$ \\
\hline \multicolumn{3}{|l|}{ Age } \\
\hline$\leq 60$ years & 732 & $57.50 \%$ \\
\hline$>60$ years & 541 & $42.50 \%$ \\
\hline \multicolumn{3}{|l|}{ Gender } \\
\hline Male & 680 & $53.42 \%$ \\
\hline Female & 593 & $46.58 \%$ \\
\hline \multicolumn{3}{|l|}{ Race } \\
\hline White & 1022 & $80.28 \%$ \\
\hline Black & 131 & $10.29 \%$ \\
\hline Others & 120 & $9.43 \%$ \\
\hline \multicolumn{3}{|l|}{ Prime Site } \\
\hline Head & 417 & $32.76 \%$ \\
\hline Body & 169 & $13.28 \%$ \\
\hline Tail & 469 & $36.84 \%$ \\
\hline Others & 218 & $17.12 \%$ \\
\hline \multicolumn{3}{|l|}{ Surgical Procedures } \\
\hline Enucleation & 20 & $1.57 \%$ \\
\hline Partial Pancreatectomy & 736 & $57.82 \%$ \\
\hline Total Pancreatectomy & 136 & $10.68 \%$ \\
\hline Whipple & 348 & $27.34 \%$ \\
\hline Surgery NOS & 33 & $2.59 \%$ \\
\hline \multicolumn{3}{|l|}{ Size } \\
\hline$\leq 2 \mathrm{~cm}$ & 347 & $27.26 \%$ \\
\hline$>2 \mathrm{~cm}$ & 926 & $72.74 \%$ \\
\hline \multicolumn{3}{|l|}{ Lymph Node } \\
\hline Negative & 742 & $58.29 \%$ \\
\hline Positive & 531 & $41.71 \%$ \\
\hline \multicolumn{3}{|l|}{ SEER Grade } \\
\hline I & 784 & $61.59 \%$ \\
\hline II & 185 & $14.53 \%$ \\
\hline III & 95 & $7.46 \%$ \\
\hline IV & 16 & $1.26 \%$ \\
\hline Unclear & 193 & $15.16 \%$ \\
\hline \multicolumn{3}{|l|}{ AJCC stage 6th } \\
\hline I & 493 & $38.73 \%$ \\
\hline II & 513 & $40.30 \%$ \\
\hline III & 24 & $1.89 \%$ \\
\hline IV & 243 & $19.09 \%$ \\
\hline
\end{tabular}

NOS, not otherwise specified; SEER Grade [34]; AJCC, American Joint Committee on Cancer.

presented significantly (both $P<0.001)$ shorter OS $(81.004$ months \pm 3.257 months and 82.245 months \pm 2.648 months, respectively) (Figure 3B and 3C). The univariate analysis demonstrated that LNR $>0.20$ and LNR $>0.07$ significantly (both $P<0.001$ ) increased the risk of death $(\mathrm{HR}=2.095,95 \%$ CI: $1.561-2.812$ and $\mathrm{HR}=1.962,95 \%$ 
CI: 1.496-2.574, respectively). However, the multivariate analysis failed to show that LNR $>0.20$ and LNR $>0.07$ were associated with OS (Supplementary Table 1).

\section{The independent prognostic factors and predictive power}

Besides LNR $>0.40$, the multivariate analysis also confirmed that age $>60$ years $(P<0.001)$, advanced SEER grade (grade III, $P<0.001$; grade IV, $P=0.008$ ) and AJCC TNM staging (stage III, $P=0.008$; stage IV, $P$ $<0.001)$ were the adverse predict factors of OS in pNENs; and female $(P=0.003)$, tumor located in body $(P=$ $0.008)$ or tail $(P=0.031)$ were the beneficial factors. This prognosis model (age, gender, tumor primary site, SEER grade, AJCC TNM staging and LNR) had acceptable discrimination (Harrell's concordance index, 0.731, 95\% CI: 0.689-0.773); and it was significantly better than SEER grade (Harrell's concordance index, 0.636, 95\% CI: 0.597-0.676) or AJCC TNM staging (Harrell's concordance index, 0.636, 95\% CI: 0.599-0.673).

\section{The LNR and clinicopathological characteristics}

The Spearman's rank correlation showed a high LNR was positive correlated with an advanced AJCC TNM staging $\left(\mathrm{r}_{\mathrm{s}}=0.604, P<0.001\right)$. Similarly, the higher LNR showed positive correlation with bigger tumor size $\left(\mathrm{r}_{\mathrm{s}}=0.273, P<0.001\right)$ and advanced SEER grade $\left(\mathrm{r}_{\mathrm{s}}=0.136, P<0.001\right)($ Table 3$)$.

\section{DISCUSSION}

Currently, the AJCC and the European Neuroendocrine Tumor Society staging classification use the regional lymph node metastasis as a prognostic indicator of pNENs [21]. However, several studies proved contrary conclusions [22-25]. The conflicting results may be due to the incomplete lymphadenectomy or inadequate histopathological examination [26]. As the total number of ELNs rises, the number of metastatic lymph nodes also rises; and previous study demonstrated the number of ELNs were associated with the accuracy of lymph node

International Classification of Diseases for Oncology, Third Edition (ICD-O-3) $8013,8041,8150,8151,8152,8153,8155,8156,8157,8240,8241,8242,8243$, $8246,8249(\mathrm{~N}=7,972)$

Excluded: patients without pathological confirmation $(\mathrm{n}=186)$; without lymphadenectomy or the number of lymph node examined unclear $(n=5205)$; the number of lymph node metastasis unclear $(n=3)$; tumor size unclear $(n=595)$; patients with unclear data of AJCC $6^{\text {th }}$ TNM stage or race $(n=651)$; without pancreatic resection $(n=43)$; small-cell $(8041)$ and large-cell neuroendocrine carcinoma (8013) of the lung $(n=16)$

\section{1, 273 patients (ICD-O-3: 8246 neuroendocrine carcinoma) included in the present study}

Figure 1: Flowchart of patients selection process. 
Table 2: Univariate and multivariate Cox regression analysis (LNR cut-off value, 0 and 0.40 )

\begin{tabular}{|c|c|c|c|c|c|c|c|}
\hline \multirow{2}{*}{ Variable } & \multirow{2}{*}{$N$} & \multicolumn{3}{|c|}{ Univariate } & \multicolumn{3}{|c|}{ Multivariate } \\
\hline & & $P$-value* & HR & $95 \% \mathrm{CI}$ & $P$-value & HR & $95 \% \mathrm{CI}$ \\
\hline \multicolumn{8}{|l|}{ Age } \\
\hline$\leq 60$ years & 732 & \multicolumn{3}{|c|}{ reference } & \multicolumn{3}{|c|}{ reference } \\
\hline$>60$ years & 541 & $<0.001$ & 2.040 & $1.567-2.655$ & $<0.001$ & 2.186 & $1.665-2.871$ \\
\hline \multicolumn{8}{|l|}{ Gender } \\
\hline Male & 680 & \multicolumn{3}{|c|}{ reference } & \multicolumn{3}{|c|}{ reference } \\
\hline Female & 593 & 0.003 & 0.663 & $0.507-0.868$ & 0.003 & 0.659 & $0.502-0.864$ \\
\hline \multicolumn{8}{|l|}{ Race } \\
\hline White & 1022 & \multicolumn{3}{|c|}{ reference } & & & \\
\hline Black & 131 & 0.457 & 0.840 & $0.530-1.331$ & & & \\
\hline Other & 120 & 0.334 & 0.777 & $0.466-1.296$ & & & \\
\hline \multicolumn{8}{|l|}{ Site } \\
\hline Head & 417 & \multicolumn{3}{|c|}{ reference } & \multicolumn{3}{|c|}{ reference } \\
\hline Body & 169 & 0.008 & 0.494 & $0.294-0.828$ & 0.008 & 0.492 & $0.290-0.833$ \\
\hline Tail & 469 & 0.041 & 0.729 & $0.538-0.987$ & 0.031 & 0.710 & $0.519-0.970$ \\
\hline Other & 218 & 0.163 & 0.768 & $0.530-1.113$ & 0.180 & 0.768 & $0.522-1.130$ \\
\hline \multicolumn{8}{|l|}{ Surgical Procedures } \\
\hline Enucleation & 20 & \multicolumn{3}{|c|}{ reference } & & & \\
\hline PP & 736 & 0.413 & 0.618 & $0.196-1.952$ & & & \\
\hline $\mathrm{TP}$ & 136 & 0.693 & 1.268 & $0.390-4.120$ & & & \\
\hline Whipple & 348 & 0.846 & 1.121 & $0.354-3.549$ & & & \\
\hline Surgery NOS & 33 & 0.341 & 0.483 & $0.108-2.161$ & & & \\
\hline \multicolumn{8}{|l|}{ Tumor Size } \\
\hline$\leq 2 \mathrm{~cm}$ & 347 & \multicolumn{3}{|c|}{ reference } & & & \\
\hline$>2 \mathrm{~cm}$ & 926 & 0.006 & 1.650 & $1.155-2.358$ & & & \\
\hline \multicolumn{8}{|c|}{ Lymph Node Metastasis } \\
\hline Negative & 742 & \multicolumn{3}{|c|}{ reference } & & & \\
\hline Positive & 531 & $<0.001$ & 1.914 & $1.467-2.497$ & & & \\
\hline \multicolumn{8}{|c|}{ Number of Examined Lymph Nodes } \\
\hline$\leq 12$ & & \multicolumn{3}{|c|}{ reference } & & & \\
\hline$>12$ & & 0.074 & 1.276 & $0.977-1.667$ & & & \\
\hline \multicolumn{8}{|l|}{ SEER Grade } \\
\hline I & 784 & & refere & & & refere & \\
\hline II & 185 & 0.491 & 1.166 & $0.754-1.802$ & 0.623 & 1.118 & $0.718-1.740$ \\
\hline III & 95 & $<0.001$ & 5.073 & $3.516-7.321$ & $<0.001$ & 3.645 & $2.501-5.310$ \\
\hline IV & 16 & $<0.001$ & 4.071 & $1.886-8.789$ & 0.008 & 2.876 & $1.320-6.270$ \\
\hline Unknown & 193 & 0.001 & 1.752 & $1.259-2.438$ & 0.003 & 1.665 & $1.193-2.324$ \\
\hline AJCC Stage 6th & & & & & & & \\
\hline I & 493 & & & & & refere & \\
\hline II & 513 & 0.001 & 1.906 & $1.319-2.754$ & 0.128 & 1.411 & $0.906-2.197$ \\
\hline III & 24 & 0.001 & 3.457 & $1.620-7.376$ & 0.008 & 2.933 & $1.325-6.490$ \\
\hline IV & 243 & $<0.001$ & 3.972 & $2.736-5.766$ & $<0.001$ & 3.297 & $2.089-5.203$ \\
\hline
\end{tabular}




\section{Lymph Node Ratio}

\begin{tabular}{llllllll}
$\mathrm{LNR}=0$ & 742 & \multicolumn{4}{c}{ reference } & \multicolumn{3}{c}{ reference } \\
$0<\mathrm{LNR} \leq 0.40$ & 369 & 0.001 & 1.665 & $1.233-2.249$ & 0.621 & 1.095 & $0.765-1.567$ \\
$\mathbf{L N R}>\mathbf{0 . 4 0}$ & 162 & $<0.001$ & 2.445 & $1.749-3.419$ & $\mathbf{0 . 0 1 2}$ & $\mathbf{1 . 6 5 0}$ & $\mathbf{1 . 1 1 7 - 2 . 4 3 8}$
\end{tabular}

*Only factor with $P$-value $\leq 0.05$ was included in multivariate analysis; variable and $P$-value in bold mean statistically significant in multivariate analysis. PP, Partial Pancreatectomy; TP, Total Pancreatectomy; NOS, not otherwise specified; SEER Grade [34]; AJCC, American Joint Committee on Cancer.
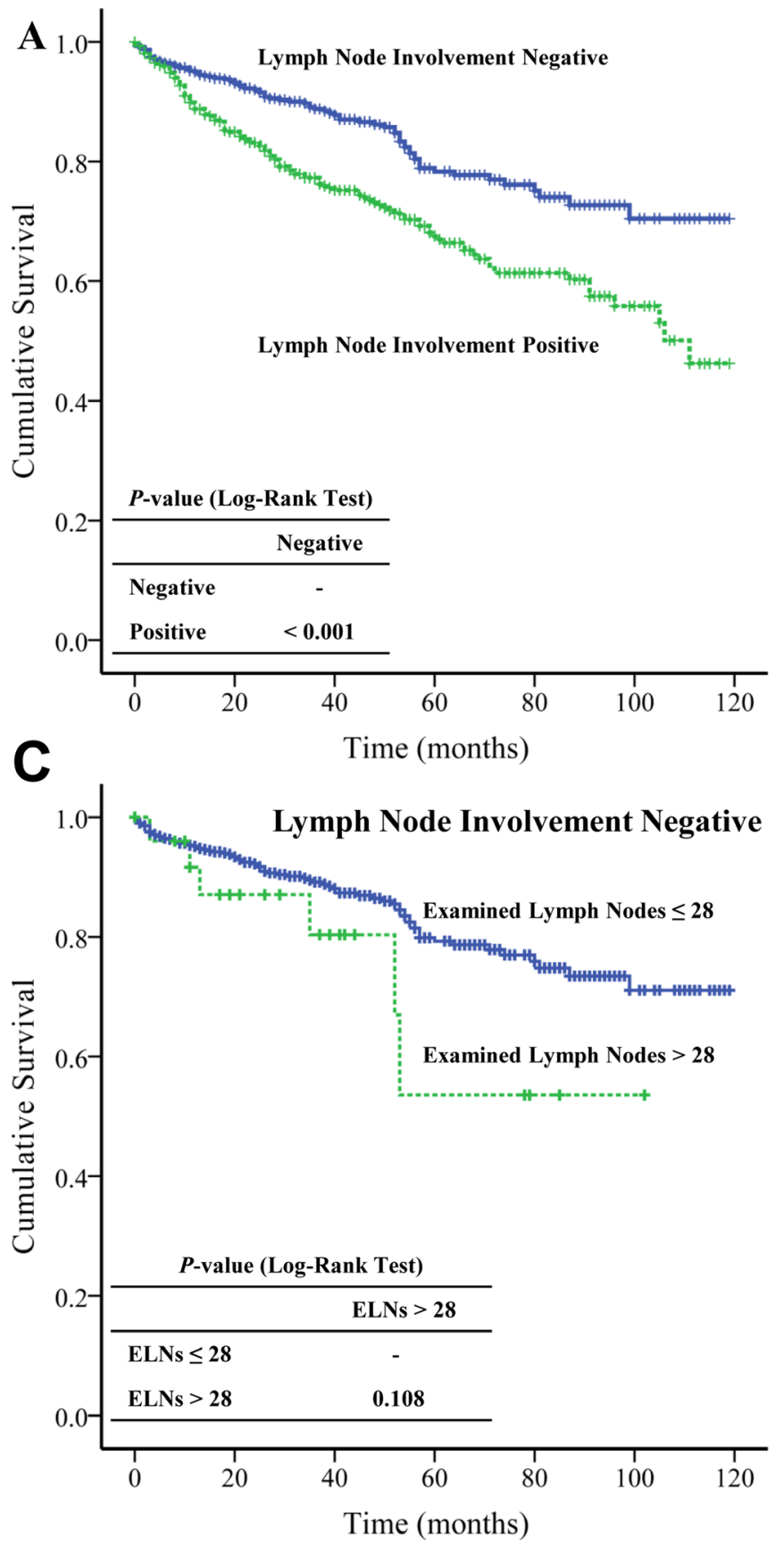

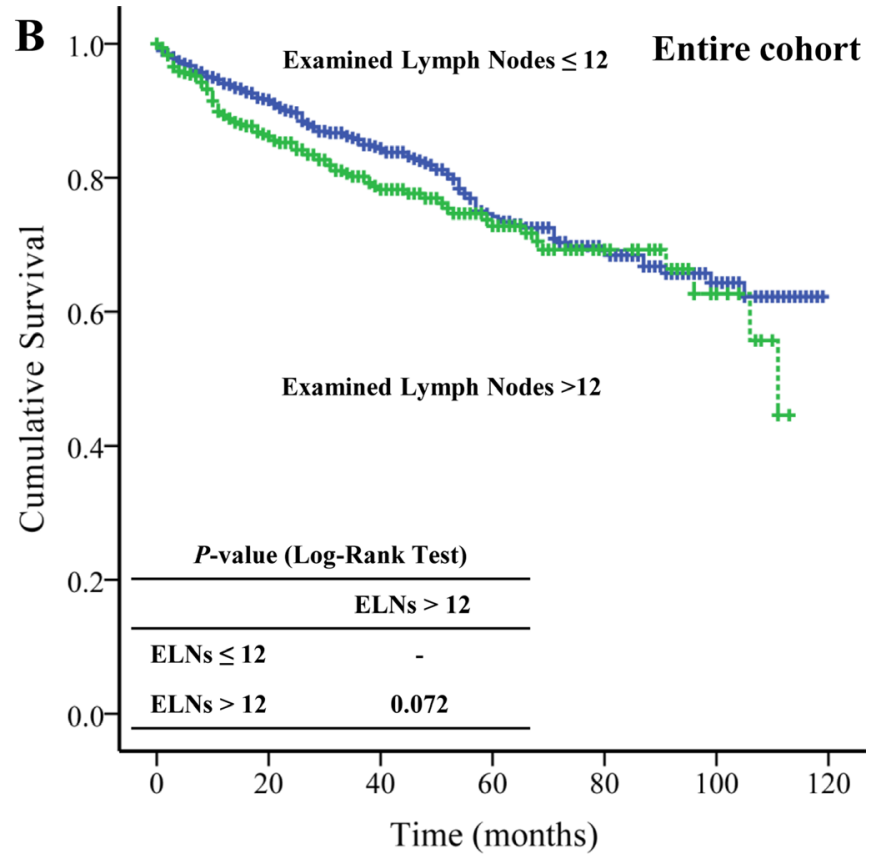

No. at Risk

\begin{tabular}{lcccccc}
\hline Months & 0 & 20 & 40 & 60 & 80 & 100 \\
\hline Negative & 742 & 450 & 251 & 144 & 74 & 28 \\
Positive & 531 & 340 & 210 & 121 & 65 & 30 \\
\hline
\end{tabular}

\begin{tabular}{lcccccc}
\hline Months & 0 & 20 & 40 & 60 & 80 & 100 \\
\hline ELNs $\leq 12$ & 795 & 510 & 305 & 186 & 104 & 45 \\
ELNs $>12$ & 478 & 280 & 156 & 79 & 35 & 13 \\
\hline
\end{tabular}

\begin{tabular}{lcccccc}
\hline Months & 0 & 20 & 40 & 60 & 80 & 100 \\
\hline ELNs $\leq 28$ & 716 & 434 & 241 & 140 & 72 & 27 \\
ELNs $>28$ & 26 & 16 & 10 & 4 & 2 & 1 \\
\hline
\end{tabular}

Figure 2: The Kaplan-Meier and log-rank tests of overall survival based on (A) lymph node metastasis; (B) the extent of examined lymph nodes of entire cohort; and (C) pNENs without lymph node metastasis. 
Table 3: Clinicopathological characters correlations with lymph node ratio (LNR)

\begin{tabular}{|c|c|c|c|c|c|}
\hline Variable & $\begin{array}{l}\text { LNR }=0 \\
(N=742)\end{array}$ & $\begin{array}{c}0<\mathrm{LNR} \leq 0.4 \\
(N=369)\end{array}$ & $\begin{array}{c}\text { LNR }>0.4 \\
(N=162)\end{array}$ & $P$-value & $\mathbf{r}_{\mathrm{s}}$ \\
\hline Tumor Size & & & & $<0.001^{\&}$ & 0.273 \\
\hline$\leq 2 \mathrm{~cm}$ & $278(37.5 \%)$ & $55(14.9 \%)$ & $14(8.6 \%)$ & & \\
\hline$>2 \mathrm{~cm}$ & $464(62.5 \%)$ & $314(85.1 \%)$ & $148(91.4 \%)$ & & \\
\hline SEER Grade & & & & $<0.001^{\&}$ & 0.136 \\
\hline I & $487(65.6 \%)$ & $219(59.3 \%)$ & $78(48.1 \%)$ & & \\
\hline II & $108(14.6 \%)$ & $58(15.7 \%)$ & $19(11.7 \%)$ & & \\
\hline III & $32(4.3 \%)$ & $41(11.1 \%)$ & $22(13.6 \%)$ & & \\
\hline IV & $6(0.8 \%)$ & $7(1.9 \%)$ & $3(1.9 \%)$ & & \\
\hline AJCC stage 6th & & & & $<0.001^{\&}$ & 0.604 \\
\hline I & $493(66.4 \%)$ & $0(0 \%)$ & $0(0 \%)$ & & \\
\hline II & $166(22.4 \%)$ & $251(68.0 \%)$ & $96(59.3 \%)$ & & \\
\hline III & $11(1.5 \%)$ & $9(2.4 \%)$ & $4(2.5 \%)$ & & \\
\hline IV & $72(9.7 \%)$ & $109(29.5 \%)$ & $62(38.3 \%)$ & & \\
\hline
\end{tabular}

SEER Grade [34]; AJCC, American Joint Committee on Cancer; ${ }^{\&}$ Spearman's rank correlation, $\mathrm{r}_{\mathrm{s}}$ correlation coefficient; Variable and $P$-value in bold mean statistically significant.

staging and OS in PDAC, especially in patients without lymph node metastasis [15]. Thus, the International Study Group on Pancreatic Surgery recommended that at least 12 lymph nodes should be examined for PDAC [27].

In the present study, we only included patients underwent lymphadenectomy and the median of ELNs was 10 (IQR, 5-16). The most appropriate cut-off value of ELNs for entire cohort and pNENs without lymph node metastasis were 12 and 28, respectively. Surprisingly, we found the extent of ELNs failed to demonstrate any survival benefit in entire cohort (ELNs $>12$ vs. ELNs $\leq 12$ ) or in the negative lymph node metastasis pNENs (ELNs $>28$ vs. ELNs $\leq 28$ ). Similar to our findings, Conrad et al. [28] also demonstrated that the extent of ELNs $(E L N s \geq 10)$ failed to show significant survival advantage.

As mentioned by previous studies [7, 8], we also found the OS of pNENs with lymph node metastasis (82.965 months \pm 2.504 months) was significantly $(P<$ 0.001 ) shorter than that of $\mathrm{pNENs}$ without lymph node metastasis ( 97.615 months \pm 2.093 months). Moreover, the lymph node metastasis significantly $(P<0.001)$ increased the risk of death $(\mathrm{HR}=1.914 ; 95 \% \mathrm{CI}: 1.467-2.497)$. However, the multivariate analysis failed to show lymph node metastasis was an independent prognostic factor in pNENs.

Recently, LNR has been demonstrated as a superior prognostic parameter than lymph node metastasis in PDAC [10, 11, 15], bladder [29], esophageal [30], and colon cancers [31]. Boninsegna et al. [19] and Ricci et al. [20] also demonstrated that LNR was an independent prognostic factor of recurrence in pNENs. However, Murakami et al. [8] reported LNR was not an independent prognostic factor of OS in pNENs.
We included 1,273 pathologically confirmed pNENs in our study and the most appropriate cut-off value of LNR was 0.40 . The Kaplan-Meier and log-rank test demonstrated the OS of pNENs with LNR $>0.40$ (75.473 months \pm 4.287 months) was significantly shorter than that of pNENs with LNR $=0$ (97.615 months \pm 2.086 months, $P<0.001)$ and $0<\mathrm{LNR} \leq 0.40$ (86.468 months \pm 3.006 months, $P=0.025)$, respectively; not only the univariate analysis but also the multivariate analysis showed LNR was an independent prognostic factor. To our knowledge, the present study is the largest population-based study to assess the OS benefit of LNR in pNENs.

Ricci et al. [20] and Boninsegna et al. [19] reported LNR $>0.07$ and LNR $>0.20$ were independent adverse predictors of recurrence, respectively. However, they did not discuss the relationship between LNR and OS. We found that compared to $\mathrm{LNR}=0, \mathrm{LNR}>0.07$ and $\mathrm{LNR}$ $>0.20$ also significantly (both $P<0.001$ ) increased the risk of death $(\mathrm{HR}=1.962,95 \% \mathrm{CI}: 1.496-2.574$; $\mathrm{HR}=$ 2.095, 95\% CI: 1.561-2.812, respectively). However, the multivariate analysis failed to show LNR $>0.07$ or LNR $>0.20$ was an independent prognostic factor of OS. Our findings were consistent with those of Murakami et al. [8]. The authors reviewed the records of 119 consecutive patients with pancreatic ductal carcinoma and they also found LNR $>0.2$ was not an independent prognostic factor of OS.

In contrast to pNENs, several studies had demonstrated LNR $>0.2$ was an independent negative prognostic factor of $\mathrm{OS}$ in PDAC [32, 33]. The contradictory results can notably be explained by the relatively indolent physiological behavior of pNENs. $\mathrm{pNENs}$ are characterized by long term survival, even if 
lymph node metastases are present. Thus, the low cut-off value of LNR (0.20) may limit the identification of LNR in $\mathrm{OS}$

Besides LNR > 0.40, age older than 60 years, advanced AJCC stage, and SEER grade, the multivariate Cox regressions also demonstrated that male and primary tumor located in pancreatic head were associated with poor outcome. This is probably due to that the carcinoid syndrome was more frequently in female patients; and this increased the likelihood of diagnosis and surgical
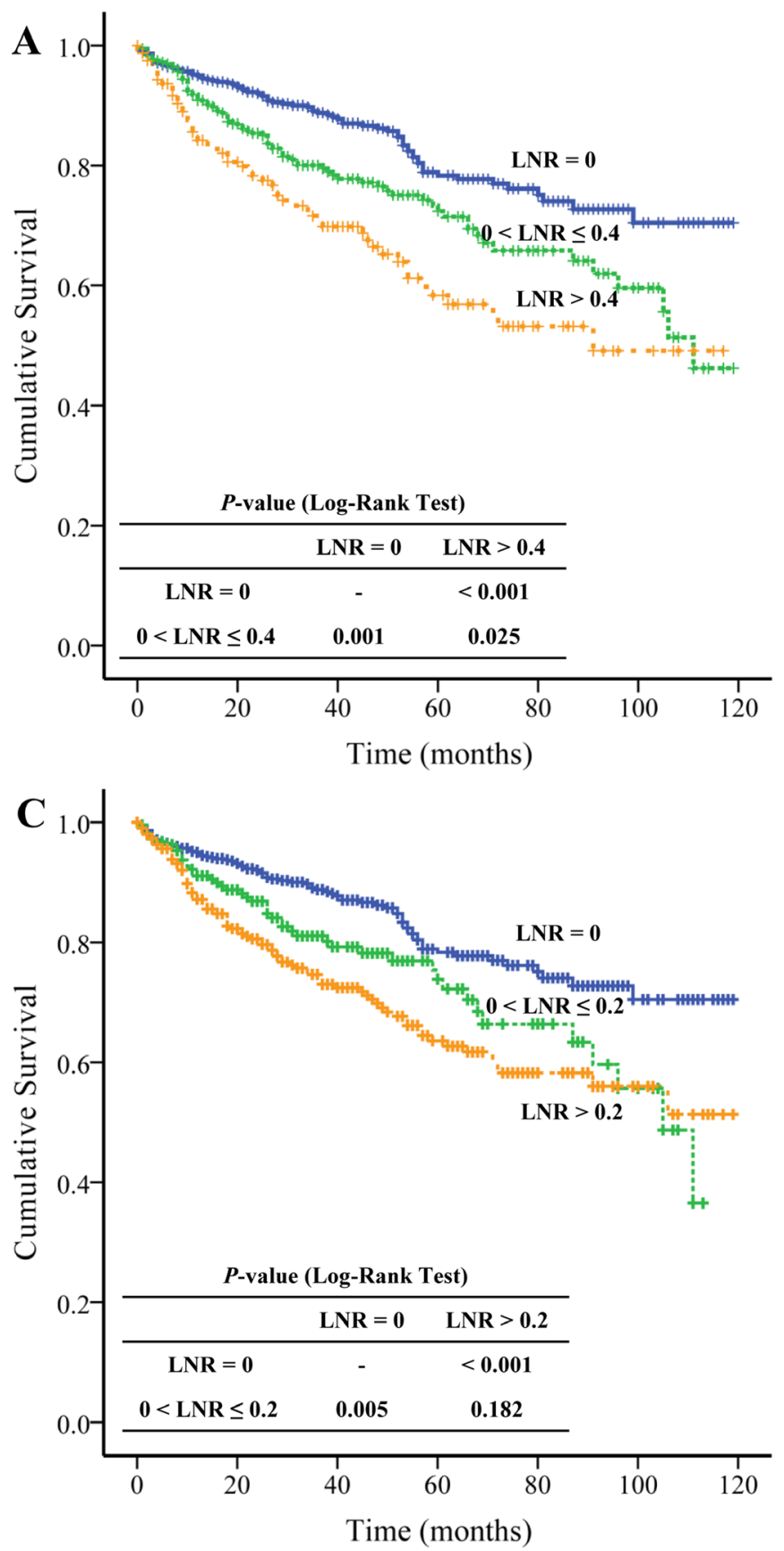

treatment in the early lesions for female patients [34]. Hashim et al. [35] reported that compared to pancreas body or tail, the head was more likely associated with lymph node metastasis; and this can explain the adverse prognostic role of primary tumor located in pancreas head.

We also found that the higher LNR was positively correlated with bigger tumor size, advanced AJCC stage, and SEER grade. To our knowledge, this is the first study to investigate the correlation between LNR and clinicopathological features.

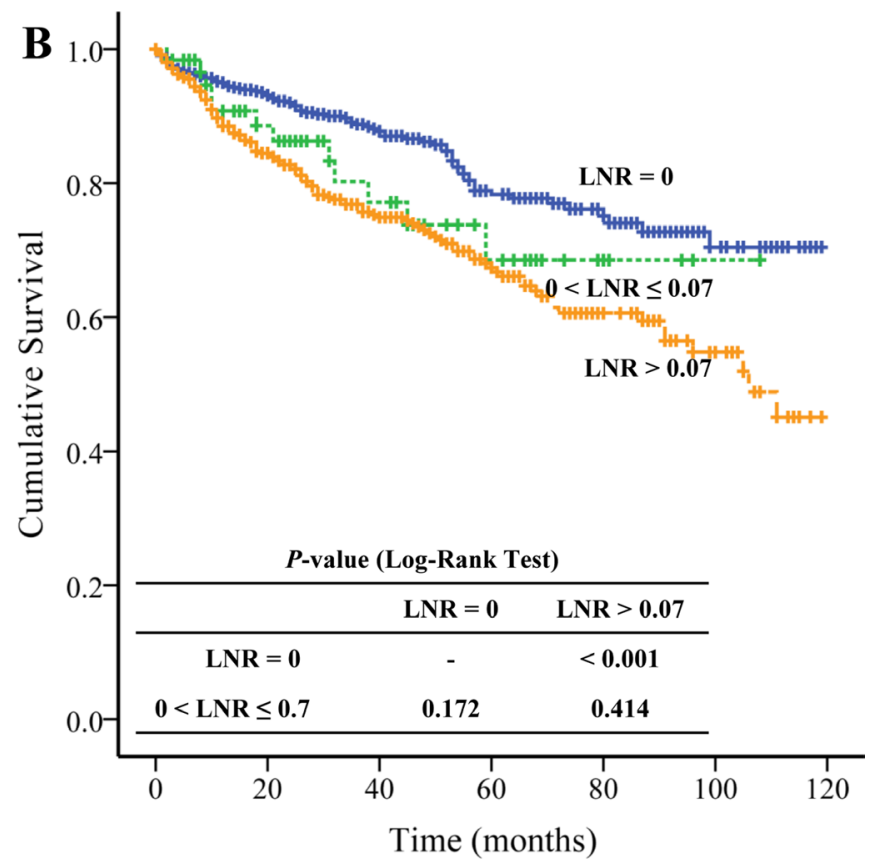

No. at Risk

\begin{tabular}{lllllll}
\hline Months & 0 & 20 & 40 & 60 & 80 & 100 \\
\hline LNR $=0$ & 742 & 450 & 251 & 144 & 74 & 28 \\
$0<$ LNR $\leq 0.4$ & 369 & 230 & 135 & 81 & 43 & 22 \\
LNR $>0.4$ & 162 & 110 & 75 & 40 & 22 & 8 \\
\hline
\end{tabular}

\begin{tabular}{lcccccc}
\hline Months & 0 & 20 & 40 & 60 & 80 & 100 \\
\hline LNR $=0$ & 742 & 450 & 251 & 144 & 74 & 28 \\
0 $<$ LNR $\leq 0.07$ & 63 & 39 & 25 & 13 & 5 & 1 \\
LNR $>0.07$ & 468 & 301 & 185 & 108 & 60 & 29 \\
\hline
\end{tabular}

\begin{tabular}{lllllll}
\hline Months & 0 & 20 & 40 & 60 & 80 & 100 \\
\hline LNR $=0$ & 742 & 450 & 251 & 144 & 74 & 28 \\
0 $<$ LNR $\leq 0.2$ & 225 & 144 & 83 & 49 & 26 & 13 \\
LNR $>0.2$ & 306 & 196 & 127 & 72 & 39 & 17 \\
\hline
\end{tabular}

Figure 3: The Kaplan-Meier and log-rank tests of overall survival based on different cut-off values of lymph node ratio. 
Notably, there were several limitations to our study. First, due to the constraints of the SEER database, we failed to evaluate the role of Ki-67, mitotic index, lymphovascular invasion, resection margin in OS. Second, this was a retrospective study; thus, the selection bias was inevitable.

In summary, our study demonstrated that it was LNR, not the number of ELNs or lymph node metastasis, proved to be an independent prognostic indicator. In the future, it is better to take into account the LNR for the pNENs staging classification; and further prospective study is needed to determine these findings.

\section{MATERIALS AND METHODS}

\section{Patient population}

To identify the pancreatic tumor, the topography codes (C25 Pancreas, C25.0-C25.9) of International Classification of Diseases for Oncology, Third Edition (ICD-O-3) were used. Then the pNEN cases were retrieved based on the following morphology codes: 8013 large cell neuroendocrine carcinoma, 8041 small cell carcinoma, 8150 islet cell carcinoma, 8151 malignant beta cell tumor, 8152 malignant alpha cell tumor, 8153 malignant gastrinoma, 8155 VIPoma, 8156 somatostatin cell tumor, 8157 malignant enteroglucagonoma, 8240 carcinoid, 8241 argentaffin carcinoid tumor, 8242 enterochromaffin cell tumor, 8243 mucocarcinoid tumor, 8246 neuroendocrine carcinoma, and 8249 atypical carcinoid tumor.

\section{Inclusion and exclusion criteria}

Only patients microscopically diagnosed as pNENs and underwent surgical resection were included. Cases without precise data for the following variables were excluded: race, tumor size, the number of lymph node metastasis or ELNs, and AJCC TNM staging. Large cell neuroendocrine carcinoma (ICD-O-3, 8013) and small cell carcinoma (ICD-O-3, 8041) mostly originating from lung were also excluded [3].

\section{Outcome and variables}

The primary outcome was OS and the following variables were considered as potential prognostic factors of OS: age; gender (male and female); race (white, black. other: American Indian/AK Native, Asian/Pacific Islander and unknown); primary tumor site (head, body, tail, other: islets of Langerhans, other specified parts of pancreas, overlapping lesion of pancreas, not otherwise specified); surgical procedures (enucleation, partial pancreatectomy, total pancreatectomy, whipple, surgery not otherwise specified); tumor size; lymph node metastasis; ELNs; LNR; SEER grade and AJCC TNM staging (sixth edition).
Not all of the SEER registries reported tumor grade according to the WHO 2010 classification [36]. Therefore, SEER database used four tumor grades based on the basis of morphological description (ICD-O-3) in pathology report: SEER grade I including tumors classified as well differentiated; grade II including those classified as moderately differentiated; grade III including those classified as poorly differentiated, and grade IV including those classified as undifferentiated or anaplastic [34].

\section{The cut-off value of continuous variables}

Age and tumor size were defined as two-category variable according to previous studies: age $\leq 60$ years vs. age $>60$ years [23]; tumor size $\leq 2 \mathrm{~cm}$ vs. tumor size $>2 \mathrm{~cm}$ [8]. The cut-off value of ELNs and LNR were determined according to the Youden's index [37]; and the ELNs were also analyzed as two-categories. We hypothesized that the lymph node metastasis was a prognostic factor of OS. Thus, the LNR was analyzed in three categories (LNR $=0$, LNR between 0 and cut-off value; LNR > cut-off value) and then it was also analyzed according to the cut-off value of 0.07 and 0.20 reported by Ricci et al. [20] and Boninsegna et al. [19], respectively.

\section{Data analysis and statistics}

The continuous non-normal distribution variables were expressed as median and IQR, and the categorical or ordinal variables were presented as frequencies and proportions. The OS was analyzed using the Kaplan-Meier and log-rank tests and presented as mean \pm standard deviation. Univariate (enter) and multivariate (forward stepwise regression) Cox proportional hazards models were used to identify the independent factors associated with OS. The Harrell's concordance index was used to evaluate the combined predictive power of all independent prognostic factors [38]. If the value is more than 0.70 , it can be concluded that the model has an acceptable discriminatory capability [39]. Spearman's rank correlation coefficient, $r_{s}$, was used to quantify the correlation between LNR and clinicopathological characteristics. $r_{s}$ ranged from -1 to +1 , where -1 indicates a perfect negative association of ranks, zero indicates no association between ranks and +1 refers to a perfect association of ranks. All statistical analyses were performed using SPSS version 19.0 (IBM Corporation. Armonk, NY, USA). $P$-value $\leq 0.05$ was considered statistically significant.

\section{Abbreviations}

pNENs: pancreatic neuroendocrine neoplasms; PDAC: pancreatic ductal adenocarcinoma; LN: lymph node; ELNs: examined lymph nodes; LNR: lymph node ratio; SEER: Surveillance, Epidemiology, and End Results; OS: overall survival; AJCC TNM stage: American Joint Committee on Cancer Stage, Sixth Edition. 


\section{Authors' contributions}

Peng Liu, Xianbin Zhang and Brigitte Vollmar write the manuscript. Xianbin Zhang, Zhaohui Tang, and Peng Gong designed the study. Peng Liu and Fei Cao collected data. Yuru Shang, Lili Lu and Min Sun analyzed data. All authors approved the final version.

\section{ACKNOWLEDGMENTS AND FUNDING}

This study was supported by grants from the National Natural Science Foundation of China (NO.81473504) and China Scholarship (NO.201608080195).

We thank the support of Dr. Weiguo Xu and Dr. Yumei Yan for the first version of our manuscript.

\section{CONFLICTS OF INTEREST}

All authors declare that no conflicts of interest exits in the submission of this manuscript.

\section{REFERENCES}

1. Halfdanarson TR, Rabe KG, Rubin J, Petersen GM. Pancreatic neuroendocrine tumors (PNETs): incidence, prognosis and recent trend toward improved survival. Ann Oncol. 2008; 19:1727-1733.

2. Lepage C, Bouvier AM, Phelip JM, Hatem C, Vernet C, Faivre J. Incidence and management of malignant digestive endocrine tumours in a well defined French population. Gut. 2004; 53:549-553.

3. Yao JC, Hassan M, Phan A, Dagohoy C, Leary C, Mares JE, Abdalla EK, Fleming JB, Vauthey JN, Rashid A. One hundred years after "carcinoid": epidemiology of and prognostic factors for neuroendocrine tumors in 35,825 cases in the United States. J Clin Oncol. 2008; 26:3063-3072.

4. Bilimoria KY, Talamonti MS, Tomlinson JS, Stewart AK, Winchester DP, Ko CY, Bentrem DJ. Prognostic score predicting survival after resection of pancreatic neuroendocrine tumors: analysis of 3851 patients. Ann Surg. 2008; 247:490-500.

5. Fischer L, Bergmann F, Schimmack S, Hinz U, Prieß S, Müller-Stich BP, Werner J, Hackert T, Büchler MW. Outcome of surgery for pancreatic neuroendocrine neoplasms. Br J Surg. 2014; 101:1405-1412.

6. Ferrone CR, Finkelstein DM, Thayer SP, Muzikansky A, Fernandez-delCastillo C, Warshaw AL. Perioperative CA19-9 levels can predict stage and survival in patients with resectable pancreatic adenocarcinoma. J Clin Oncol. 2006; 24:2897-2902.

7. Krampitz GW, Norton JA, Poultsides GA, Visser BC, Sun L, Jensen RT. Lymph nodes and survival in pancreatic neuroendocrine tumors. Arch Surg. 2012; 147:820-827.

8. Murakami Y, Uemura K, Sudo T, Hayashidani Y, Hashimoto Y, Nakashima A, Yuasa Y, Kondo N, Ohge H,
Sueda T. Number of metastatic lymph nodes, but not lymph node ratio, is an independent prognostic factor after resection of pancreatic carcinoma. J Am Coll Surg. 2010; 211:196-204.

9. Strobel O, Hinz U, Gluth A, Hank T, Hackert T, Bergmann F, Werner J, Buchler MW. Pancreatic adenocarcinoma: number of positive nodes allows to distinguish several $\mathrm{N}$ categories. Ann Surg. 2015; 261:961-969.

10. Baldwin S, Kukar M, Gabriel E, Attwood K, Wilkinson N, Hochwald SN, Kuvshinoff B. Pancreatic cancer metastatic to a limited number of lymph nodes has no impact on outcome. HPB (Oxford). 2016; 18:523-528.

11. Riediger H, Keck T, Wellner U, zur Hausen A, Adam U, Hopt UT, Makowiec F. The lymph node ratio is the strongest prognostic factor after resection of pancreatic cancer. J Gastrointest Surg. 2009; 13:1337-1344.

12. Hellan M, Sun CL, Artinyan A, Mojica-Manosa P, Bhatia S, Ellenhorn JD, Kim J. The impact of lymph node number on survival in patients with lymph node-negative pancreatic cancer. Pancreas. 2008; 37:19-24.

13. Schwarz RE, Smith DD. Extent of lymph node retrieval and pancreatic cancer survival: information from a large US population database. Ann Surg Oncol. 2006; 13:1189-1200.

14. Showalter TN, Winter KA, Berger AC, Regine WF, Abrams RA, Safran H, Hoffman JP, Benson AB, MacDonald JS, Willett CG. The influence of total nodes examined, number of positive nodes, and lymph node ratio on survival after surgical resection and adjuvant chemoradiation for pancreatic cancer: a secondary analysis of RTOG 9704. Int J Radiat Oncol Biol Phys. 2011; 81:1328-1335.

15. Slidell MB, Chang DC, Cameron JL, Wolfgang C, Herman JM, Schulick RD, Choti MA, Pawlik TM. Impact of total lymph node count and lymph node ratio on staging and survival after pancreatectomy for pancreatic adenocarcinoma: a large, population-based analysis. Ann Surg Oncol. 2008; 15:165-174.

16. Partelli S, Fernandez-Del Castillo C, Bassi C, Mantovani W, Thayer SP, Crippa S, Ferrone CR, Falconi M, Pederzoli P, Warshaw AL, Salvia R. Invasive intraductal papillary mucinous carcinomas of the pancreas: predictors of survival and the role of lymph node ratio. Ann Surg. 2010; 251:477-482.

17. Tol JA, Brosens LA, van Dieren S, van Gulik TM, Busch OR, Besselink MG, Gouma DJ. Impact of lymph node ratio on survival in patients with pancreatic and periampullary cancer. Br J Surg. 2015; 102:237-245.

18. Falconi M, Crippa S, Dominguez I, Barugola G, Capelli P, Marcucci S, Beghelli S, Scarpa A, Bassi C, Pederzoli P. Prognostic relevance of lymph node ratio and number of resected nodes after curative resection of ampulla of Vater carcinoma. Ann Surg Oncol. 2008; 15:3178-3186.

19. Boninsegna L, Panzuto F, Partelli S, Capelli P, Delle Fave G, Bettini R, Pederzoli P, Scarpa A, Falconi M. Malignant pancreatic neuroendocrine tumour: lymph node 
ratio and $\mathrm{Ki} 67$ are predictors of recurrence after curative resections. Eur J Cancer. 2012; 48:1608-1615.

20. Ricci C, Casadei R, Taffurelli G, Buscemi S, D`Ambra M, Monari F, Santini D, Campana D, Tomassetti P, Minni F. The role of lymph node ratio in recurrence after curative surgery for pancreatic endocrine tumours. Pancreatology. 2013; 13:589-593.

21. Cho JH, Ryu JK, Song SY, Hwang JH, Lee DK, Woo SM, Joo YE, Jeong S, Lee SO, Park BK, Cheon YK, Han J, Kim TN, et al. Prognostic validity of the American Joint Committee on Cancer and the European Neuroendocrine Tumors Staging Classifications for pancreatic neuroendocrine tumors: A retrospective nationwide multicenter study in South Korea. Pancreas. 2016; 7:941-946.

22. Boyar Cetinkaya R, Vatn M, Aabakken L, Bergestuen DS, Thiis-Evensen E. Survival and prognostic factors in welldifferentiated pancreatic neuroendocrine tumors. Scand J Gastroenterol. 2014; 49:734-741.

23. Wong J, Fulp WJ, Strosberg JR, Kvols LK, Centeno BA, Hodul PJ. Predictors of lymph node metastases and impact on survival in resected pancreatic neuroendocrine tumors: a single-center experience. Am J Surg. 2014; 208:775-780.

24. Kim JY, Kim MS, Kim KS, Song KB, Lee SH, Hwang DW, Kim KP, Kim HJ, Yu E, Kim SC, Jang HJ, Hong SM. Clinicopathologic and prognostic significance of multiple hormone expression in pancreatic neuroendocrine tumors. Am J Surg Pathol. 2015; 39:592-601.

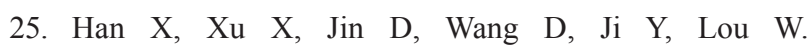
Clinicopathological characteristics and prognosis-related factors of resectable pancreatic neuroendocrine tumors: a retrospective study of 104 cases in a single Chinese center. Pancreas. 2014; 43:526-531.

26. Parekh JR, Wang SC, Bergsland EK, Venook AP, Warren RS, Kim GE, Nakakura EK. Lymph node sampling rates and predictors of nodal metastasis in pancreatic neuroendocrine tumor resections: the UCSF experience with 149 patients. Pancreas. 2012; 41:840-844.

27. Tol JA, Gouma DJ, Bassi C, Dervenis C, Montorsi M, Adham M, Andrén-Sandberg A, Asbun HJ, Bockhorn M, Büchler MW, Conlon KC, Fernández-Cruz L, Fingerhut A, et al. Definition of a standard lymphadenectomy in surgery for pancreatic ductal adenocarcinoma: a consensus statement by the International Study Group on Pancreatic Surgery (ISGPS). Surgery. 2014; 156:591-600.

28. Conrad C, Kutlu OC, Dasari A, Chan JA, Vauthey JN, Adams DB, Kim M, Fleming JB, Katz MH, Lee JE. Prognostic value of lymph node status and extent of lymphadenectomy in pancreatic neuroendocrine tumors confined to and extending beyond the pancreas. J Gastrointest Surg. 2016; 20:1966-1974.
29. Kassouf W, Agarwal PK, Herr HW, Munsell MF, Spiess PE, Brown GA, Pisters L, Grossman HB, Dinney CP, Kamat AM. Lymph node density is superior to TNM nodal status in predicting disease-specific survival after radical cystectomy for bladder cancer: analysis of pooled data from MDACC and MSKCC. J Clin Oncol. 2008; 26:121-126.

30. Wang N, Jia Y, Wang J, Wang X, Bao C, Song Q, Tan B, Cheng Y. Prognostic significance of lymph node ratio in esophageal cancer. Tumour Biol. 2015; 36:2335-2341.

31. Parnaby C, Scott N, Ramsay G, MacKay C, Samuel L, Murray G, Loudon M. Prognostic value of lymph node ratio and extramural vascular invasion on survival for patients undergoing curative colon cancer resection. Br J Cancer. 2015; 113:212-219.

32. Pawlik TM, Gleisner AL, Cameron JL, Winter JM, Assumpcao L, Lillemoe KD, Wolfgang C, Hruban RH, Schulick RD, Yeo CJ, Choti MA. Prognostic relevance of lymph node ratio following pancreaticoduodenectomy for pancreatic cancer. Surgery. 2007; 141:610-618.

33. Hartwig W, Hackert T, Hinz U, Gluth A, Bergmann F, Strobel O, Büchler MW, Werner J. Pancreatic cancer surgery in the new millennium: better prediction of outcome. Ann Surg. 2011; 254:311-319.

34. Halperin DM, Shen C, Dasari A, Xu Y, Chu Y, Zhou S, Shih YT, Yao JC. Frequency of carcinoid syndrome at neuroendocrine tumour diagnosis: a population-based study. Lancet Oncol. 2017; 18:525-534.

35. Hashim YM, Trinkaus KM, Linehan DC, Strasberg SS, Fields RC, Cao D, Hawkins WG. Regional lymphadenectomy is indicated in the surgical treatment of pancreatic neuroendocrine tumors (PNETs). Ann Surg. 2014; 259:197-203.

36. Niederle MB, Hackl M, Kaserer K, Niederle B. Gastroenteropancreatic neuroendocrine tumours: the current incidence and staging based on the WHO and European Neuroendocrine Tumour Society classification: an analysis based on prospectively collected parameters. Endocr Relat Cancer. 2010; 17:909-918.

37. Habibzadeh F, Habibzadeh P, Yadollahie M. On determining the most appropriate test cut-off value: the case of tests with continuous results. Biochem Med (Zagreb). 2016; 26:297-307.

38. Harrell FE Jr, Califf RM, Pryor DB, Lee KL, Rosati RA. Evaluating the yield of medical tests. JAMA. 1982; 247:2543-2546.

39. Holter JC, Ueland T, Jenum PA, Müller F, Brunborg C, Frøland SS, Aukrust P, Husebye E, Heggelund L. Risk factors for long-term mortality after hospitalization for community-acquired pneumonia: A 5-year prospective follow-up study. PLoS One. 2016; 11:e0148741. 